\title{
КРИЗИС ДУХОВНОСТИ: ПРОЗАИЗАЦИЯ БЫтия
}

\section{В.С. Писчиков, М.М. Холин}

Деятельность человека лишена однозначной естественной предзаданности. Она не запрограммирована полностью биологическими механизмами, подобно жизнедеятельности животных, но релевантна и относительно социальных условий. Повседневная и перспективная жизненные программы разрабатываются индивидом в большей или меньшей степени сознательно и свободно. Поэтому и целесообразность его отдельных действий и поступков в рамках этих программ, а также выбор необходимых для их осуществления путей и средств - следствие осознанного, осмысленного отношения индивида к самому себе, другим и миру в целом. Но смыслы действий и используемых для достижения целей средств, как правило, не изобретаются индивидом по своему усмотрению, а определяются культурой, в которой он существует. Причем смыслы многих явлений и артефактов культуры неоднозначны, полифоничны, что открывает перед индивидом не только возможность их свободного выб̆ора, но и сотворчества в процессе трансформации или созидания новых смыслов.

При этом культурным смыслам присуща как бы двухуровневость, двухплановость, которая отражает различие между непосредственным и опосредованным их аспектами. Первый аспект связан с функциональным характером осуществляемых индивидом действий и используемых им вещей, обусловлен непосредственными их мотивами, целями и назначением. Второй же-определяется нефункциональными и неутилитарными целями и ценностями (моральными, эстетическими, религиозными, идеологическими и др.), дополняет и может содержательно изменять первый. В органическом, а порою и противоречивом

Актуальні проблеми духовності

(Відп. ред.: Я.В. Шрамко)

Кривий Pir (2008), 12-23 
единстве эти аспекты, уровни образуют единый, целостный смысл человеческих действий, поступков, используемых вещей.

Отмеченная способность человека к удвоению смыслов вызвана, на наш взгляд, двумя основными причинами: потребностью индивида в субъективной сопричастности к бытию целого (социальной группы, социума, культуры), а также его стремлением уйти от голого функционализма и утилитарности в своей жизни, придать ей тем самым более значимый и высокий смысл. Эту функцию в культуре осуществляет духовность, порождающая один из важнейших атрибутов человеческого бытия - его одухотворенность.

История первобытной культуры человечества свидетельствует, что потребность в одухотворении свого бытия появ.ляется у человека не сразу, а на определенном этапе развития общества. Так, наскальная живопись первобытного человека, как утверждают специалисты, первоначально имела магический характер и ее назначением было воздействие на изображаемые объекты (чаще всего животных) в утилитарных целях. Аналогично танцы и сопровокдавшие их песни вначале выступали в качестве своеобразной репетиции, «проигрывания» разнообразных ситуаций, возникающих в трудовой деятельности, защите от врага или нападении на него.

Таким образом, эти, как и многие другие, подобные им явления культуры сначала заключали в себе лишь функциональный, утилитарный жизненный смысл. Духовный же (әстетический) их смысл, который в настоящее время и стал для них основным, появляется позже, на определенном уровне развития сознания первобытного человека, культуры общества. Таковы были и первые моральные нормы и понятия, о чем в частности свидетельствует этимология таких этических категорий, как добро (от брать), счастье (от часть) и др.

Появившаяся уже в первобытном обществе потребность человека в одухотворении своего бытия имела исключительно важное для него значение: она позволила ему преодолеть восприятие своей жизни как только бнологического существования и тем самым отграничить ее от жизнедеятельности животных. Благодаря этому человек сумел увидеть как в своей жизни в целом, так и в конкретньх ее проявлениях нечто большее, чем их материальная суть и функциональная, биологическая по своей интенции, целесообразность. Это дало возможность человеку существенно раздвинуть границы исторической перспективы своего развития как родового существа. Перед ним открылся путь бесконечного духовного развития, а не только совершенствования себя как природного существа - своего тела, способов удовлетворения его 
инстинктивных влечений и потребностей.

Хотя функцию одухотворения человеческого бытия с әтого исторического момента стала выполнять вся формирующаяся духовная культура в целом, особую роль в этом сыграли вначале миф, а позже религия, мораль и искусство как основные сферы духовности.

Моральные понятия, нормы и идеалы, а также соответствующие им чувства и эмоции ориентировали индивида на преодоление утилитарного и эгоистического в себе и своих взаимоотношениях с другими, на восприятие другого человека как ценности. Любовь, сострадание, доброта, бескорыстие постепенно стали возводиться моральным сознанием общества в ранг высших ценностей, одухотворяющих человеческую жизнь.

Формируя понятия и чувства красоты и гармонии, искусство вносило эстетическое начало в бытие человека, придавая его экзистенциалам высокий жизненный смысл. Рождение и смерть, любовь и дружба, труд и ратный подвиг представали в мифах и легендах, танцах и песнях, пословицах и поговорках в одухотворенной форме. Это одухотворение реалий повседневности давало возможность индивиду воспринимать их сквозь призму поэтической образности, романтичности, преображая тем самым «прозу жизни».

Органичная включенность духовности в повседневную жизнь человека сохранялась вплоть до общественного разделения труда на физический и умственный. Возникновение в связи с этим духовного производства как относительно самостоятельной сферы деятельности, а затем все большая его автономизация и профессионализация имели противоречивые последствия для духовной жизни общества. С одной стороны, появились объективные условия для более динамичного и успешного развития духовной культуры, создания выдаюшихся образцов духовности, которые в принципе невозможно создать в процессе повседневной жизни. С другой стороны, выделение духовной деятельности в особую, профессиональную сферу существенно обедняло духовный потенциал жизни тех, кто был занят по преимуществу материальной деятельностью. Причем это негативное следствие еще более усиливалось и обострялось причинами классового характера, которые объективно препятствовали движению духовных ценностей из сферы профессиональной деятельности, где они создаются, в повседневную жизнь низших классов и слоев, то есть большинства общества.

В сложившихся условиях духовного отчуждения важнейшее значение приобрело существовавшее с первобытных времен, непосредственно включенное в повседневную жизнь народное творчество: в духов- 
ной жизни - фольклор, а в сфере материальной деятельности - художественные ремесла. Именно народное творчество, синтезирующее в органичный сплав разнообразные духовные ценности, становится с этого исторического момента основным источником одухотворения повседневной жизни народа и одновременно основной сферой его духовной самореализации. Более того, народное творчество постепенно превращается в важнейший источник профессионального творчества, что свидетельствует о его высоких моральных и эстетических достоинствах.

Наметившаяся тенденция снижения уровня духовности повседневной жизни, ее прозаизация усилились с радикальными изменениями в положении человека в материальном производстве и содержании его труда, которые происходят в условиях перехода от ремесла к машинному производству. Включение в связи с этим человека в качестве элемента в технологический процесс и подчинение его машине, упрощение содержания его труда имели своим следствием снижение интеллектуального и творческого потенциала трудовой деятельности. В условиях фактически пожизненной профессионализации и специализации, а также отчуждения труда эти изменения весьма негативно отразились не только на духовном развитии индивида как личности и индивидуальности, но также на укладе его жизни и социальной среде, снижая уровень их одухотворенности.

Отмеченные негативные изменения в сфере трудовой материальной деятельности осуществлялись в социальном контексте коренной трансформации природы общественных отношений. Формирующиеся буржуазные отношения, которые, по выражению Маркса, срывали со всего и вся ореол возвышенности, утверждали в обществе культ денег, приоритет прагматического расчета и успеха. Все это расширило масштабы и придало ускорение процессу прозаизации бытия. Начавшийся в повседневной жизни этот процесс, закрепляясь в ценностях техногенной цивилизации, охватывает всю сферу духовной культуры, включая и професснональное искусство - один из важнейших источников духовности общества. Постепенно из сферы искусства вытесняется духовность и человечность как ее основа. Обративший одним из первых внимание на это известный в свое время на Западе теоретик искусства, русский философ В.В.Вейдле в 30-е гг. ХХ столетия констатировал: «Неудивительно, что в таком искусстве отсутствует самый образ человека; или оно в лучшем случае пользуется им, как всяким другим материалом, для своих упражнений» [3, с. 289].

Этот процесс несколько позже Ортега-и-Гассет назовет «поворо- 
том к бес-человечному» в искусстве, его «дегуманизацией»: «Пытаясь определить общеродовую и наиболее характерную черту нового творчества я обнаруживаю тенденцию к дегуманизации искусства» $[7$, c. 241]. Хотя испанский философ и характеризует новое искусство как «явление весьма двусмысленное», в целом он позитивно оценивает тенденцию дегуманизации, полагая, что она ведет к нанболее адекватному проявлению природы искусства и его личностного предназначения: «Искусство, освободившись от человеческой патетики, лишилось какой бы то ни было трансценденции, осталось только искусством - без претензии на большее» $[7$, с. 257,260$]$.

Принципиально иной была оценка тенденции дегуманизации искусства В.В. Вейдле. Он характеризует этот процесс как «умирание искусства», выделяя в качестве важнейшего его признака бездуховность, которую он связывает с особенностями современного общества: «Судьба искусства, судьба современного мира - одно. Там и тут бездуховная сплоченность всего утилитарного, массового, управляемого вычисляюшим рассудком, противопоставляется распыленности личного начала» $[3$, с. 290]. Значительно позже лауреат Нобелевской премии по литературе, выдающийся немецкий писатель Г. Бёлль также укажет на социальные корни дегуманизации искусства, отметив, что в современной западной культуре «практикуется и пропагандируется, как мне кажется, самоубийственное отвержение человеческого и общинного» $[1$, c. 303$]$.

В этой дискуссии истина, на наш взгляд, на стороне В.В.Вейдле и Г. Бёлля. Дегуманизированное искусство объективно не способно осуществлять функцию одухотворения человеческого бытия, внесения в него высших смыслов, духовных принципов и идеалов, рассматривая это как чуждую себе «патетику» и «трансценденцию». Более того, обладая исключительными техническими возможностями, распространения и воздействия на духовный мир человека, современное искусство все эффективнее выполняет прямо противоположную функцию - сводит высшие духовные ценности к бнологически обусловленным страстям и механизмам, психологическим мотивам и практическим целям. Усиление и утверждение данной тенденции в духовной культуре современного общества связано прежде всего с влиянием постмодернизма, которым «был сделан следующий шаг - в направлении смены системообразующего центра современной культуры как перехода от слова к телу, от интеллектуальности и духовности к телесности, от вербальности к зрительному образу, от рациональности к новой архаике, когда в центре ментальности и дискурса оказываются тело и 
плоть» $[9$, c. 37].

В результате такой подмены ценностей искусство не только перестает быть источником духовности, но, напротив, способствует разрушению одухотворенного образа бытия, который веками поддерживался традиционной классической культурой, облагораживавшей «прозу повседневности». Осознание опасности для бытия человека и бесперспективности для самого искусства тенденции дегуманизации и бездуховности характерно для многих мыслителей и художников, которые видят выход в возврате искусства к выработанным на протяжении тысячелетий подлинным духовным ценностям. Так, в противоположность постмодернистской тенденции в искусстве, поступал Г. Бёлль, следуя своей «эстетике человеческого». Он стремился одухотворить в своих произведениях такие реалии повседневности, как «обитание, соседство и родина, деньги и любовь, религия и застолье», изображая их «в тех точках высокого напряжения ..., где вещественное становится духовным, телесное - душевным, физиологическое и социологическое - индикатором этики и эстетики» [1, с. 293, 339].

Говоря о состоянии и тенденциях развития духовности современного общества, безусловно, не следует, как недоценивать, так и переоценивать роль искусства в этом. То, что оно имеет большое, едва ли не определяющее значение в формировании эстетического сознания, эстетических вкусов и потребностей, - это очевидно сейчас, в эпоху высокого уровня развития средств массовой информации. Однако ясно и то, что эстетическое как в обыденном сознании, так и в искусстве неразрывно связано с этическим. Так, вульгарность и пошлость в одинаковой мере характеризуют развитие не только эстетического вкуса, но и моральных качеств личности. Причем ведущим здесь, как и в других аналогичных случаях, является этическое: личность с развитым моральным сознанием не приемлет вульгарного не только в искусстве, но и где бы то ни было в жизни.

Следовательно, бездуховность в искусстве - это в не меньшей, а возможно, и в большей степени проблема моральная, нежели эстетическая. Даже художник, вполне искренне провозгласивший и принявший имморализм в качестве своей эстетической позиции и беспристрастно, как ему кажется, изображающий в своих произведениях добро и зло, неизбежно эстетизирует зло и тем самым, не желая того, объективно становится на его сторону. Что же тогда говорить об этической направленности произведений тех «творцов духовности», которые вполне осознанно выбирают позицию аморализма? Поэтому есть все основания утверждать: бездуховность приобрела такие масштабы в современном 
искусстве потому, что произошла девальвация моральных ценностей его творцов, в сознании и жизненной позиции которых место служения искусству заняло служение своим весьма далеким от него эгоистическим корыстным интересам и целям.

Однако степень моральности, как и духовности в целом, творцов искусства не обусловлена исключительно процессом его внутреннего развития, не является независимой от социума величиной. Напротив, это величина в решающей степени определяется состоянием духовности общества. Общепризнанным является кризис духовности в современном обществе, в частности, снижение ее уровня в повседневной жизни людей. В последнее десятилетие в социально-философской литературе этому феномену уделяется все более пристальное внимание, с ним связывается укоренение или деградация духовности в обществе. Теоретический анализ понятия повседневности, предпринятый И.Т.Касавиным и С.П.Шавелевым, обнаружил его содержательную сложность и многослойность (см.: [5]).

Рассматриваемая в онтологическом аспекте повседневность выступает как «природно-телесное и лично-общественное бытие (поведение) человека, ... необходимая предпосылка (общий компонент) всех остальных форм существования и деятельности людей» $[5$, с. 20, 22]. Традиционно повседневность, как правило, связывается со сферой быта и включенного в нее досуга людей, что, по сути, верно. Однако нередко упускается из вида то, что повседневность не существует как четко очерченная и строго ограниченная от других сфера человеческой жизни: «Повседневности во всех ее ипостасях, как правило, не соответствует некоторая автономная сфера; не существует субстанция повседневности. Все ипостаси повседневности - не самодостаточны, не существуют вне иных проявлений человеческого бытия и сознания», констатируют в этой связи И.Т. Касавин и С.П. Щавелев [5, с. 414].

Повседневность может выходить далеко за пределы быта, проникая в другие, нередко противоположные ей, сферы жизнедеятельности человека, как только деятельность в них приобретает характер каждодневного, привычного занятия. Поэтому «свои собственные будни неизбежно возникнут даже у тех, чья жизнь волею судьбы или характера - почти сплошь праздники и ритуалы либо приключения или катастрофы» [5, с. 24].

Содержательные признаки повседневности, характер ее воздействия на развитие индивида и ее восприятия им неоднозначны. Безусловно, упрощенным является устоявшийся взгляд на повседневность как реальность, которая заслуживает для своего описания исключитель- 
но негативных эпитетов. Ведь «будни бывают не только безлики, но порой в чем-то достаточно разнообразны ... Из череды будней нельзя исключать случайности, неожиданности, а следовательно, и тут есть некие инновации, творческие моменты, включая познавательные» [5, c. 24]. С этим невозможно не согласиться. Но нечего возразить, по сути, и против того, что основное пространство и время повседневности как реальности представляют собой повторяюшуюся череду привычных дел, проблем и забот, связанных по преимуществу с материальной стороной жизни человека. Поэтому у человека и существует потребность если не в преодолении, то хотя бы в уменьшении, сведении к минимуму однообразия и монотонности повседневной жизни. Издавна формами такого разнообразия повседневности выступают игра, праздники, ритуалы, хобби и др., через которые в повседневность традиционно вносилась и духовность.

Социальные трансформации, прошедшие в ХХ столетии, радикально изменили ситуацию. Важнейшей из них является утверждение в современном обществе потребительства в качестве доминирующего образа жизни. В сочетании с возросшей динамикой жизненных перемен потребительство радикально преобразовало содержание и структуру всей системы ценностей человеческого бытия, выдвинув на передний план материальные ценности, в частности, витальные. К тому жеи это не менее важно - потребительство как жизненная ориентация и психологическая установка придало многим объектам потребления знаковый характер: «Система потребления ... является системой манипуляции знаками»,- отмечает в связи с этим Ж. Бодрийяр [2, с. 14].

Объекты потребления, как материальные, так и духовные, индивидом-потребителем воспринимаются не столько в качестве предметов, удовлетворяющих определенные его потребности, сколько в качестве знаков, за которыми стоит нечто более важное для него-статус в обществе, успех и связи, престиж и мода и др. То есть при этом «предмет утрачивает свою объективную целесообразность, свою функцию» и, следовательно, «истина современного предмета состоит не в том, чтобы служить для чего-то, но чтобы значить ..., быть знаком» $[2$, c. 150, 154]. Посредником в данном процессе между индивидом-потребителем и потребляемыми ценностями выступают современные средства массовой информации. Именно через них субъектами, управляющими системой потребления, которая функционирует отнюдь не стихийно, задаются определенные ценностные ориентации, формируются знаки, репрезентирующие разнообразные явления действительности. Моделируемая таким способом реальность оказывается весьма дале- 
кой от действительности, так как отражает лишь ее внешнюю сторону и лишена ее подлинного внутреннего смысла. Как отмечает в связи с этим Ж. Бодрийяр, «массовые коммуникации дают нам не действительность, а головокружение от действительности. Мы живем, таким образом, под покровом знаков и в отказе от действительности» $[2$, c. 15$]$.

Естественно, что подлинные духовные ценности не могут выступать в качестве аксиологического основания конструируемой индивидом знаковой реальности, которая входит в его повседневную жизнь. Более того, у индивида не возникает и потребности в таких ценностях, так как он вполне удовлетворяется их знаками, представленными в масс-медиа. Исключительную роль в этом играют мода и реклама, моделирующие знаковое «царство небытия»: «Реклама (и другие средства массовой информации) нас не обманывает: она находится по ту сторону истинного и ложного, как мода находится по ту сторону безобразного и красивого» $[2$, с. 166$]$.

Гипердинамизм реалий повседневной жизни и потребительское сознание в условиях растущего социального отчуждения личности вырабатывают у нее противоречивое восприятие времени. С одной стороны, скоротечность и кратковременность этих реалий, невозможность для личности их контролировать формируют у нее психологическую установку жить сегодняшним днем, то есть настоящим, вследствие чего обесценивается непреходящее, вечное: «Современному сознанию чуждо и недоступно понятие вечности . .., для сегодняшнего ходячего представления вечность - это бесконечно продолжающееся время» $[4$, c. 414,415$]$.

С другой стороны, осознание той же скоротечности жизненных условий вне связи их с непреходящим обесценивает и настоящее, воспринимающееся индивидом как всего лишь кратковременный эпизод, который неизбежно, и весьма скоро, уступит место другому. Поэтому, как отмечает П.П. Гайденко, для современного человека «определяющим модусом времени становится не настоящее, не момент „menерь" как неделимое, вневременное начало времени, сквозь которое, как сквозь окно, виден проблеск вечности, то есть подлинного бытия, а будущее - то, чего нет» $[4$, с. 18$]$.

Однако эта субъективная ориентация на будущее не связана с восприятием его как желаемого, «лучшего будущего». В ситуации непрочности, зыбкости настоящего будущее предстает как вызывающая тревогу и беспокойство неизвестность. Тем самым, на наш взгляд, есть основания констатировать состояние кризиса в восприятии современ- 
ным человеком времени в целом, а не только отдельных его модусов. Проблематичность будущего, обесценивание настоящего и вечного неизбежно ведут к девальвации подлинных духовных ценностей, их релятивизации и субъективизации. Объективной основой этого процесса являются изменения в темпоральности окружающего человека мира вещей - нарастающая его недолговечность, что имеет первостепенное значение для индивида-потребителя: «Мы переживаем время вещей ..., мы живем в их ритме и в соответствии с их непрерывной последовательностью. Сегодня мы видим, как они рождаются, совершенствуются и умирают, тогда как во всех предшествовавших цивилизациях именно вещи, инструменты и долговечные монументы жили дольше, чем поколения людей» $[2$, с.5].

Эта особенность современного вещного мира обусловлена не его собственными и не антропологическими, а объективными социальными причинами, среди которых прежде всего интересы капитала: в условиях насыщения рынка товарами и связанной с этим все более жесткой конкуренции новизна (товаров, услуг, духовных ценностей в статусе товаров) становится едва ли не главным достоинством вещей. Для создания и поддержания этого имиджа новому широко используются такие эффективные инструменты, как уже упоминавшиеся мода и реклама. Они формируют у индивида-потребителя через средства массовой информации ориентацию на новизну как психологическую установку: «Новое ищется не потому, что старое оказалось нежизненным и неплодотворным, но просто ради самой новизны, новое требуется любой ценой»,- констатирует ситуацию современный немецкий философ Г. Зельдмайр (цит. по: [4, с. 418]).

Принципиально соглашаясь с данной оценкой, отметим, что, на наш взгляд, все же не новизна сама по себе является для индивида-потребителя самоценностью, а то, что стонт за ней. Новое воспринимается с подачи масс-медиа как знак престижного, современного, прогрессивного и именно они являются настоящей ценностью для потребителя, свидетельствуя ему о его личной состоятельности.

Таким образом, в системе потребительства не только подлинные духовные ценности потребляются в качестве знаков. Таков же удел и ценностей, порождаемых потребительским образом жизни.

Возможности насыщения повседневной жизни знаками духовности в настоящее время многократно расширились, что стало следствием развития и всевластия современных средств массовой информации, особенно телевидения и в последнее время интернета. Это, безусловно, не могло не способствовать в значительной степени преодолению 
консерватизма, замкнутости, рутинности и монотонности повседневной жизни, более широкому включению в нее элемента игры, праздничности, новизны. Однако эстетические и этические качества массовой культуры, транслируемой масс-медиа, знаковый характер ее подачи и восприятия индивидом не только не способствуют возрастанию уровня духовности повседневного бытия, но, напротив, усугубляют тенденцию ее прозаизации.

В таких условиях вряд ли обоснован оптимизм тех, кто, признавая, что «для современной ситуации характерна утрата духовности, ожесточение нравов, жесткий прагматизм», склонны тем не менее надеяться, что «все эти внешние характеристики могут быть временными и относительным проявлением сложного процесса накопления опыта, примеривания и адаптации человека к изменившимся социальным условиям его бытия» [8, с. 185]. Без коренного преобразования общественных отношений и ликвидации вместе с әтим потребительства как системы жизненных ценностей и образа жизни, на наш взгляд, радикально переломить ситуацию невозможно. Реально лишь некоторое замедление темпов и уменьшение масштабов процесса бездуховности как результата сознательных, целенаправленных усилий всех тех, кому дороги подлинная духовность и культура. Среди них наиболее широкими возможностями для этого обладают работники сферы образования и воспитания, масс-медиа, творцы искусства, - словом все те, кто создает и контролирует культурно-информационное пространство, «по меркам которого выкроены и запрограммированы ежедневно наши мечты и, парадоксально говоря, побеги реальности» [6, с. 138].

\section{1 Литература}

[1] Бёлль $\Gamma$. Франкфуртские чтения // Самосознание европейской культуры ХХ века: Мыслители и писатели Запада о месте культуры в современном обществе.-М., 1991.

[2] Бодрийяр ЖК. Общество потребления. Его мифы и структуры. M., 2006.

[3] Вейдле B. Умирание искусства. Размышление о судьбе литературного и художественного творчества // Самосознание европейской культуры ХХ века. - М., 1991.

[4] Гайденко П.П. Время. Длительность. Вечность. Проблема времени в европейской философии и науке. - М., 2006. 
[5] Касавин И.Т., Шавелев С.П. Анализ повседневности.-М., 2004.

[6] Оюсе $M$. Кризис смысла в современном мире // Философская и социологическая мысль. - 1995. - N56.

[7] Opmeza-u-Гассет X. Дегуманизация искусства // Самосознание европейской культуры ХХ века.-М., 1991.

[8] Тельнова H.A. Целостность человека в онтолого-антропологическом измерении. - Саратов, 2002.

[9] Тульчинский Г.Л. Слово и тело постмодернизма. От феномонологии невменяемости к метафизике свободы // Вопросы философии. - 1999. - № 10. 